\title{
WATER ACCESS, WOMEN'S EMPOWERMENT, SANITATION AND CHILDREN'S ANTHROPOMETRIC STATUS: A STUDY OF ETHIOPIAN MOTHERS WITH CHILDREN UNDER FIVE
}

\author{
DAVOD AHMADI, KATE SINCLAIR, HUGO MELGAR-QUINONEZ \& PATRICK CORTBAOUI \\ McGill Institute for Global Food Security, Canada
}

\begin{abstract}
Recent studies have shown that most African countries are overwhelmed with problems related to water access. Women are disproportionality responsible for fetching water for drinking and domestic use. Notably, fetching water has been shown to influence various aspects of women's lives. The main objective of this paper is to study the association between the amount of time mothers spend carrying water and factors such as socioeconomic characteristics, women's empowerment (i.e., decision making, group membership, attitudes toward gender equality), income-generating activities (i.e., access to land and saving money (as proxies)), maternal nutritional status (i.e., Mid Upper Arm Circumstances (MUAC), dietary diversity score), childcare practices (i.e., breastfeeding, taking children for weighting or treatment for malnutrition, and children's dietary diversity), and children's anthropometric indicators. Data from a survey carried out in Ethiopia in 2016 was used in this article. Different statistical analyses formed the basis of the work. Firstly, descriptive statistics were used to analyse the data. Secondly, bivariate analyses were used to examine the association between exposure and outcome variables. Finally, binary logistic regression analyses were conducted. Results showed significant negative associations between the time spent fetching and saving money, group membership, attitudes toward gender equality, MUAC, dietary diversity, childcare care practices, and children's anthropometric indicators. This paper supports the important link between water access and women and children's nutritional statuses.
\end{abstract}

Keywords: water access, time fetching water, women's empowerment, health.

\section{INTRODUCTION}

Between 1990 and 2012 approximately 2.3 billion people gained access to improved drinking-water [1]; nonetheless, nearly 650 million people worldwide continue to lack access to safe water supplies, the majority of which reside in developing countries [2]. In Ethiopia, water access is strongly influenced by place of residence [3] with 60 percent of rural households using unimproved sources, such as rivers, ponds and open springs [2]. Both drought and politics exacerbate water access in Ethiopia [4]. The consequences of poor water access are far reaching. In Ethiopia, poor access to water has economic, social, health, and food security effects, especially among women [5]-[8]. For individuals lacking water sources in or near home, obtaining water often involves a great expense of time and energy [9]. Worldwide, women and young children are most vulnerable to the burden of fetching water for domestic use [10]. Strategies to improve access to safe drinking water can contribute to both health and non-health benefits, especially for women and children [11], [12].

In low income countries, time fetching water has been identified as one of the determinants of women and children's health status. Evidence has shown that a reduction in minutes fetching water is associated with lower mortality rates, lower prevalence of diarrhoea, and better anthropometric indicators of child nutritional status [13]. Amongst nonhealth-related aspects of fetching water, perhaps the most notable is the time savings from not having to walk to collect water, which can lead to income-generating activities [14]. In 
Africa, women's involvement in income-generating activities remains low, some of which may be attributed to the time burden of obtaining water. In fact, statistics show that rural women and children spend approximately 40 billion hours each year fetching water in Sub Saharan Africa (SSA) [13]. These activities may constrain women's participation in education activities, as well as other productive tasks such as market-based labour [11]. Furthermore, research shows that women with poor access to water are more likely to be exposed to different types of violence, such as sexual, emotional, and physical [2].

The main objectives of this paper are (1) to examine the association between community water supply and time fetching water; (2) to examine the association between community water supply and type of water access; (3) to study the association between mothers' time spent carrying water and different features of their lives, including decision making, attitudes towards gender-equality, group membership, health and childcare practices.

\section{METHODOLOGY}

This study uses data from a baseline survey entitled Growing Nutrition for Mothers and Children (GROW), which was conducted by CARE Canada in 2016. The sample was randomly chosen from three main regions in Ethiopia, Afar, East and West Hararghe. A total of 1261 mothers with children $(<5)$ were surveyed.

Different statistical analyses formed the basis of this paper. Crosstab analyses were conducted to examine the association between community water supply and time fetching water. Community water supply was measured using the following question: "Is there any community water supply used by people in this area?" Time fetching water was recoded into two categories: 0-30 minutes and 31-481 minutes. A cut-off of 30 minutes was used because the literature argues that the total water collection time should be less than 30 minutes for basic access levels [15]. To assess the association between community water supply and type of water used for drinking, washing and sanitation types, chi-square analyses were conducted.

For analyses related to women's empowerment, time fetching water was used as the dependent variable. The following were selected as independent variables: accumulated decision making, which is a sum of six standard questions used by CARE Canada; genderequality attitudes score, which is a sum of five standard questions used by CARE Canada related to mothers' attitudes toward equality; and sum of mothers' membership in groups (yes/no), access to land last year (yes/no), saving money (yes/no), and maternal education (some/none).

For analyses related to care practices, dietary diversity and anthropometrics, time fetching water was used as the independent variable. An adjusted binary logistic regression was conducted for each dependent variable (maternal MUAC, maternal and child dietary diversity, breastfeeding, treatment for malnutrition and weighing). All analyses were also adjusted for mother's age, mother's education level, child's age, and number of children under five living in the household. Finally, T-test analyses were carried out to explore mean and standard deviation of children's anthropometric indicators with mothers' fetching time (0-30 min and 31-highest).

Dietary diversity was calculated separately for mothers and children. It was measured by asking respondents whether they had consumed items from nine distinct food groups in the past 24 hours. The final score is an unweighted summary of the binary "yes/no" answers. Dietary scores were recoded into two categories, for mothers " $0-3$ "and "4-9", and for children, "0-3" and "4-7". Mother's mid-upper arm circumstance was recoded into two categories "0-23", "24-99". Although no standard cut-off has been established for using MUCA in adults, a cut-off of less than $23 \mathrm{~cm}$ is often recommended to indicate women's 
acute malnutrition [16]. Using the WHO syntax, children were categorized as stunted, wasted, underweight and BMI-for-age based on their Z-scores for weight for height (WHZ), height-for-age (WAZ), and body-mass-index-for age (BMIZ), respectively [17].

\section{RESULTS}

Maternal socioeconomic characteristics are presented in Table 1. The sample was distributed among the three regions as follows: Afar (23\%), East Hararghe (40\%) and West Hararghe (38\%). Approximately, $90 \%$ of mothers reported living in male-headed households, and the majority of them reported having received no education (80\%). Only $36 \%$ of mothers reported working outside the home, and half of the women had access to land (50\%). Nearly all of them identified themselves as the person responsible for carrying water for domestic use $(88 \%)$. Finally, the majority reported having unimproved water for drinking $(60 \%)$, washing $(60 \%)$, and $45 \%$ reported unimproved sanitation.

Table 2 contains results of CROSSTABS analysis between mother's time fetching water and outcome variables.

Socioeconomic characteristics A significant positive association was found between maternal age and time fetching water $(0.100)(\mathrm{p}=0.006)$ and maternal working outside was negatively associated with time fetching water $(-0.115)(\mathrm{p}=0.000)$. However, no significant association was found between mother's education and time spent carrying water for household.

Women's empowerment Attitudes towards gender-equality score was negatively correlated with mothers' fetching water time $(-0.086)(\mathrm{p}=0.002)$. The strongest association was found between group membership and time spent carrying water $(-0.192)(\mathrm{p}=0.000)$.

Income-generating activities Two variables, access to land and saving money, were selected as proxy measures for maternal income-generating activities. Saving money was negatively related with time fetching water $(-0.162)(\mathrm{p}=0.000)$ and, although weak, a significant correlation was found between access to land and time carrying water $(-0.080)$ $(\mathrm{p}=0.002)$.

Table 1: Maternal and water-related characteristics $(n=1,261)$.

\begin{tabular}{|l|l|l|l|}
\hline $\begin{array}{l}\text { Maternal } \\
\text { characteristics }\end{array}$ & Region & Afar & $286(22.7)$ \\
\hline & & East Hararghe & $502(39.8)$ \\
\hline & & West Hararghe & $473(37.5)$ \\
\hline & Head of HH & Male-headed & $1120(88.8)$ \\
\hline & Education & Never attended & $996(79.2)$ \\
\hline & Work outside & Yes & $454(36.0)$ \\
\hline & Access to land & Yes & $628(49.8)$ \\
\hline & Who fetch water & Female adult and girls (<15) & $1091(87.8)$ \\
\hline & Unimproved water drinking & Yes & $693(60.3)$ \\
\hline & Unimproved wash & Yes & $694(60.22)$ \\
\hline & Type of sanitation & Unimproved & $570(45.2)$ \\
\hline Source: Self-calculation of micro-data from Survey of Ethiopia on 2016 (GROW) \\
\hline
\end{tabular}


Mothers' physical function There was a significant association between maternal MUAC and time fetching water $(-0.084)(\mathrm{p}=0.003)$; however, the strength of association was weak. Maternal dietary diversity was negatively associated with time spent carrying water for domestic use $(-0.101)(\mathrm{p}=0.000)$.

Mothers' childcare practices Taking children for treatment for malnutrition $(-0.163)$ $(\mathrm{p}=0.000)$, taking children for weighting $(-0.134)(\mathrm{p}=0.000)$, and children dietary diversity $(-$ $0.128)(\mathrm{p}=0.000)$ were all negatively correlated with mothers' time for collecting water. However, there was no significant association between breastfeeding and time collecting water for domestic use.

Findings from CROSSTABS analyses between community water supply and type of water for drinking, type of water for washing types, and sanitation types are presented in Table 3. Relatively strong associations were found between availability of water in community with types of water for drinking $(0.259)(\mathrm{p}=0.000)$, type of water for washing $(0.280)(p=0.000)$, and improved sanitation types $(0.140)(p=0.000)$.

Table 2: Bivariate analyses between mothers' fetching water time (exposure) and outcome variables $(\mathrm{n}=1,261)$.

\begin{tabular}{|c|c|c|c|}
\hline & & $\begin{array}{l}\text { Strength of } \\
\text { association }\end{array}$ & Sig. \\
\hline Community related factors & Community water supply & -0.119 & 0.000 \\
\hline \multirow[t]{3}{*}{ Socioeconomic characteristics } & Age & 0.100 & 0.006 \\
\hline & Education & 0.029 & 0.787 \\
\hline & Work outside & -0.115 & 0.000 \\
\hline \multirow[t]{3}{*}{ Related to women's empowerment } & Decision making & 0.091 & 0.116 \\
\hline & Gender-equality attitudes & -0.086 & 0.002 \\
\hline & Group membership & -0.192 & 0.000 \\
\hline \multirow[t]{2}{*}{ Income-generating activities } & Access to land & -0.080 & 0.005 \\
\hline & Saving money & -0.162 & 0.000 \\
\hline \multirow[t]{2}{*}{ Mothers' physical function } & MUAC & -0.084 & 0.003 \\
\hline & Mothers' dietary diversity & -0.101 & 0.000 \\
\hline \multirow[t]{4}{*}{ Mothers' childcare practices } & Breastfeeding & 0.009 & 0.772 \\
\hline & $\begin{array}{l}\text { Children received treatment } \\
\text { for malnutrition }\end{array}$ & -0.163 & 0.000 \\
\hline & Take children to weighting & -0.134 & 0.000 \\
\hline & Children's dietary diversity & -0.128 & 0.000 \\
\hline
\end{tabular}


Table 3: Bivariate analyses between community water supply, drinking, washing and sanitation types.

\begin{tabular}{|l|l|l|}
\hline & $\begin{array}{l}\text { Strength of } \\
\text { association }\end{array}$ & Sig. \\
\hline Water for drinking $(0=$ rain collecting; 1=Unimproved; 2: Improved $)$ & 0.206 & 0.000 \\
\hline Water for washing $(0=$ rain collecting; 1=Unimproved; 2: Improved) & 0.230 & 0.000 \\
\hline Sanitation types $(0=$ Unimproved ;1=Improved) & 0.140 & 0.000 \\
\hline $\begin{array}{l}\text { Reference: Self-calculation of micro-data from Survey of Ethiopia on 2016 (GROW) } \\
\text { Chi-square significance: } *=p<0.05 ; * *=p<0.01 ; * * *=p<0.001\end{array}$ \\
\hline
\end{tabular}

Table 4: Adjusted and unadjusted binary logistic regression between mothers' fetching water time and socioeconomic, related to women's empowerment characteristics.

\begin{tabular}{|c|c|c|c|c|c|}
\hline & & Unadjusted & \multicolumn{3}{|c|}{ Adjusted } \\
\hline & & Odd Ratio & OR & CI-L & $\mathrm{CI}-\mathrm{H}$ \\
\hline \multirow[t]{3}{*}{ Region } & Afar & $2.994 * * *$ & $2.326 * * *$ & 1.584 & 3.416 \\
\hline & East Hararghe & 1.189 & 1.084 & 0.822 & 1.43 \\
\hline & West Hararghe & Ref & & & \\
\hline \multirow[t]{4}{*}{ Age groups } & $15-24$ & 0.988 & 1.223 & 0.642 & 2.329 \\
\hline & $25-29$ & 1.370 & 1.773 & 0.951 & 3.307 \\
\hline & $30-39$ & 1.647 & $1.887^{*}$ & 1.010 & 3.524 \\
\hline & $40-49$ & Ref & & & \\
\hline \multirow[t]{2}{*}{ Education level } & Never attended. & 1.0 .34 & 0.731* & 0.533 & 1.003 \\
\hline & Having some. & Ref & & & \\
\hline \multirow[t]{2}{*}{ Working outside } & No & $1.618 * * *$ & 1.154 & 0.879 & 1.515 \\
\hline & Yes & Ref & & & \\
\hline \multirow[t]{2}{*}{ Decision making } & Others & 0.966 & 1.060 & 0.825 & 1.363 \\
\hline & Mothers & Ref & & & \\
\hline \multirow[t]{2}{*}{ Gender-equality attit } & Low & $1.430^{* *}$ & 1.071 & .827 & 1.387 \\
\hline & High & Ref & & & \\
\hline \multirow{2}{*}{ Group membership } & No & $2.205^{* *}$ & $1.368 * * *$ & 1.265 & 2.120 \\
\hline & Yes & Ref & & & \\
\hline \multirow[t]{2}{*}{ Access to land } & No & $1.383^{* *}$ & 1.000 & 0.775 & 1.2941 \\
\hline & Yes & Ref & & & \\
\hline \multirow[t]{2}{*}{ Saving money } & No & $2.065 * * *$ & $1.826 * * *$ & 1.388 & 2.401 \\
\hline & Yes & Ref & & & \\
\hline \multirow[t]{2}{*}{ Com. water supply } & No & $1.645 * * *$ & $1.415 * * *$ & 1.098 & 1.823 \\
\hline & Yes & Ref & & & \\
\hline
\end{tabular}


Results from unadjusted and adjusted binary logistic regressions analyses related to empowerment are presented in Table 4 . Results from the adjusted binary logistic regressions analyses show that mothers: from Afar $(\mathrm{OR}=2.326)(\mathrm{P}=0.000)$, between 30 and 39 years of age $(\mathrm{OR}=1.887)(\mathrm{P}=0.044)$, with no group membership $(\mathrm{OR}=1.368)(\mathrm{P}=0.000)$, and poor opportunities for saving money $(\mathrm{OR}=1.826)(\mathrm{P}=0.000)$, had significantly increased odds of spending more time carrying water for domestic use. Similarly, a community's limited access to water supply increased one's odds of spending more time collecting water $(\mathrm{OR}=1.415)(\mathrm{P}=0.000)$.

Results from the various adjusted binary logistic regression analyses between mothers' time fetching water and their health, dietary diversity score, and childcare practises are presented in Table 5. Results indicate that mothers who spend 30 minutes or less fetching water had significantly higher odds of having a MUAC of $24 \mathrm{~cm}$ or greater $(\mathrm{OR}=1.304)$ $(\mathrm{P}=0.067)$ and a dietary diversity score of four or more $(\mathrm{OR}=1.421)(\mathrm{P}=0.006)$. They also had significantly higher odds of taking their children for treatment for malnutrition $(\mathrm{OR}=2.248)(\mathrm{P}=0.000)$ and were more likely to take them for weighing $(\mathrm{OR}=2.202)$ $(\mathrm{P}=0.000)$. No significant association was found between time fetching water and breastfeeding.

Results from T-test analyses between mothers' fetching water time ( 0 to $30 \mathrm{~min}$ and 31 to highest) and children's anthropometric indicators are presented in Table 6. Significant differences were found between maternal time spent for collecting water with children's anthropometric indicators except for being underweight.

Table 5: Adjusted binary logistic regression between mothers' fetching water time and mothers' childcare practices.

\begin{tabular}{|c|c|c|c|c|c|c|c|c|c|c|c|}
\hline & & 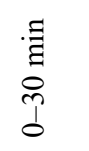 & 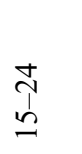 & 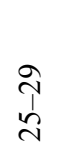 & के & $\begin{array}{l}0 \\
\tilde{z} \\
0 \\
\text { Z }\end{array}$ & $\begin{array}{l}\tilde{0} \\
\stackrel{1}{ } \\
? \\
0\end{array}$ & 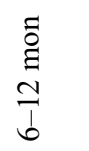 & 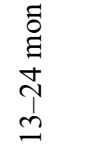 & 荧 & 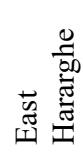 \\
\hline 1 & OR & 1.304 & 0.840 & 1.065 & 1.238 & 0.836 & 0.963 & $\begin{array}{l}0.593 \\
*\end{array}$ & 0.726 & $\begin{array}{l}0.324 \\
* * *\end{array}$ & 0.886 \\
\hline 2 & OR & $\begin{array}{l}1.421 \\
* *\end{array}$ & 1.391 & 1.297 & 1.332 & $\begin{array}{l}0.520 \\
* * *\end{array}$ & 1.132 & 1.271 & 1.104 & $\begin{array}{l}0.489 \\
* * *\end{array}$ & 0.786 \\
\hline 3 & OR & $\begin{array}{l}2.248 \\
* * *\end{array}$ & 0.782 & 0.601 & 0.598 & $\begin{array}{l}0.668 \\
*\end{array}$ & 0.505 & 0.620 & 1.015 & 0.677 & $\begin{array}{l}0.444 \\
* * *\end{array}$ \\
\hline 4 & OR & $\begin{array}{l}2.023 \\
* * *\end{array}$ & $\begin{array}{l}0.446 \\
*\end{array}$ & $\begin{array}{l}0.435 \\
*\end{array}$ & $\begin{array}{l}0.459 \\
*\end{array}$ & $\begin{array}{l}0.441 \\
* * *\end{array}$ & 0.634 & 0.723 & 1.252 & 0.730 & 0.773 \\
\hline 5 & OR & 0.760 & 1.242 & 1.441 & 1.329 & 1.179 & $\begin{array}{l}0.667 \\
* * *\end{array}$ & $\begin{array}{l}8.551 \\
* * *\end{array}$ & $\begin{array}{l}3.606 \\
* * *\end{array}$ & $\begin{array}{l}0.370 \\
* * *\end{array}$ & 0.845 \\
\hline
\end{tabular}

1. MUAC; 2. Mother's dietary diversity; 3. Children received treatments; 4. Take child for weighting; 5. Breastfeeding;

Reference: Self-calculation of micro-data from Survey of Ethiopia on 2016 (GROW); Chi-square significance: $*=p<0.05 ; * *=p<0.01 ; * * *=p<0.001$ 
Table 6: T-test analyses of mothers' time to fetching water and children's anthropometric indicators.

\begin{tabular}{|c|c|c|c|}
\hline & & $0-30 \mathrm{~min}$ & $31-480 \mathrm{~min}$ \\
\hline \multirow[t]{3}{*}{ Weight-for-height (Wasting) } & Mean & 0.25 & -0.22 \\
\hline & SD & 1.99 & 1.83 \\
\hline & & \multicolumn{2}{|c|}{$* * *$} \\
\hline \multirow[t]{3}{*}{ Height-for age (stunting) } & Mean & -1.34 & -1.39 \\
\hline & SD & 2.38 & 2.17 \\
\hline & & \multicolumn{2}{|c|}{ * } \\
\hline \multirow[t]{3}{*}{ Weight-for-age (Underweight) } & Mean & -0.67 & -0.84 \\
\hline & SD & 1.79 & 1.62 \\
\hline & & \multicolumn{2}{|c|}{ n. $\mathbf{s}$} \\
\hline \multirow[t]{3}{*}{ BMI-for-age } & Mean & 0.41 & -0.08 \\
\hline & SD & 2.02 & 1.92 \\
\hline & & \multicolumn{2}{|c|}{$* * *$} \\
\hline \multicolumn{4}{|c|}{$\begin{array}{l}\text { Reference: Self-calculation of micro-data from Survey of Ethiopia on } 2016 \text { (GROW) } \\
\text { Chi-square significance: } *=p<0.05 ; * *=p<0.01 ; * * *=p<0.001\end{array}$} \\
\hline
\end{tabular}

\section{DISCUSSION}

The importance of this work was to explore the association between amount of time Ethiopian mothers spent carrying water and different aspects of their lives, such as women's empowerment indicators, nutritional status, childcare practices, and children's anthropometric indicators.

Men and women hold different positions in our societies, which are influenced by a mix of historical, economic, cultural, economic and religious realities. When it comes to gender there exists undeniable inequalities, which usually favour men. Findings from this study show that water allocation in Ethiopia is no exception. In nearly all of the households surveyed, women and young girls were responsible for carrying water for domestic use; this is consistent with the available evidence, which shows that burden of fetching water tends to fall disproportionately on women in Ethiopia [18].

Findings highlight that the availability of water in the community is associated with the amount of time mothers spend carrying water; a finding supported by the literature [19]. Inadequate supply of water and sanitation infrastructure increases the time it takes to fetch water [20]. Hence, access to basic infrastructure contributes to a reduction in the time spent on domestic chores, including fetching of water for domestic use [21]. Mothers living in the Afar region were particularly vulnerable to the burden of lengthy water collection. Much of this can be attributed to political disregard, and poor living standards and infrastructure in the region [22].

As fetching water is typically the responsibility of women, it is hypothesized that a reduction in the time needed to access clean water could dramatically reduce the workload 
of women, thus liberating time that could be allocated to other activities. Whether they be care, or economic activities, or both, this has the potential to improve the lives of not only the women but also their families and communities. For instance, some suggest that when the time to fetch water is lengthy, women's and girl's education opportunities may be compromised, especially with regards to "absenteeism "[11], [23]. However, in this study no significant difference was found between time fetching water and levels of education. Nonetheless, part of this may be attributed to the fact that nearly 80 percent of women had never received any education.

Furthermore, water access and time fetching water have implications for maternal and child health status. Firstly, because this work is physically demanding; carrying water is an even more onerous chore than gathering firewood, and women and young girls spend countless hours bringing water home [24]. Secondly, it occupies a lot of time that could otherwise be allocated to improved childcare practices; and, when unclean, it directly exposes individuals to different diseases and pathogens [18]. The lack of improved water and sanitation, with 60 percent of women reporting the use of unimproved water sources and 45 percent reporting unimproved sanitation, is cause for concern. As explained by UNICEF [23] "poor water and sanitation, as well as unsafe hygiene practices are the main causes of diarrhea, one of the main child killers" in Ethiopia. Furthermore, mothers who reported spending 30 minutes or less fetching water had significantly higher odds of having a MUAC of $24 \mathrm{~cm}$ or more. They also were more likely to report a dietary diversity score of four or more. Improving dietary diversity is important, especially among women and children, because research shows that low dietary diversity makes individuals susceptible to micronutrient deficiencies and poor health outcomes. Women and children are particularly at-risk due to their higher micronutrient requirements [25]-[28]. Although there are a multitude of factors that can influence nutritional status, and it is not clear exactly how the aforementioned relationships work, these results help support the link between improved access to water and women's nutritional status [29].

A similar link was found among children. Significant associations were observed between time fetching water and children's anthropometric indicators statues, which is consistent with the previous studies [13]. It is thought that part of this may be due to the adoption of improved care practice with a reduction in the time needed to collect water [30].

In this regard, this study presents mixed findings in that mothers who spent less than 30 minutes on water collection were significantly more likely to take children to be treated for malnutrition and for weighing; however, with regards to breastfeeding no significant association was found. Some of these inconstancies may be explained by the fact that time is a finite resource and the trade-off of using time for care practices versus other activities is influenced by many factors and is highly individualized. For instance, for mothers who have the opportunity to use this time to work outside the home, the cost of breastfeeding their child is large relative to those who are unemployed, and, thus may choose not to prioritize this practice. Furthermore, although generally it is assumed that women's workload would decrease with improved water access, some case studies show that total working hours do not necessarily decrease after successful implementation of water programs [31], hence they might not actually have more free time to allocate to improved care practices.

In this study, women who were unemployed did not spend significantly more time fetching water, which is likely due to the fact that there are little formal employment opportunities in these areas, especially for women as a result of cultural norms. Nonetheless, women who did not at least have the opportunity to save money, be it from informal work, selling goods or other sources, which was used as a proxy measure for generating money, were more susceptible to lengthy water collection. Hence, these findings do support those of 
last cited study who state that women who spend less time fetching water have increased involvement in income-generating activities. However, in this case, the income does not seem to be attributed to work outside the home but rather to other opportunities that allow money to be saved. Women within wealthier households may spend less time on water collection because they have the means to hire someone to fetch water, have private water sources installed or own livestock, such as a donkey, to help transport water [32].

One may hypothesize that women with more decision-making autonomy, a component of empowerment, would spend less time collecting water. However, in this study, as in that of last cited study no significant association was found between mothers' decision making and time carrying water. This could be attributed to the fact that unlike making decisions about household purchases or healthcare, when it comes to water collection, households are bound to the type of water access they have, and the deep-rooted cultural norms that suggest that water collection is the responsibility of women may be more difficult to shift than others. Power relations in the household usually favour the father, or the eldest son; consequently, they tend to have control over the labour and behaviour of all household members [33]. Furthermore, woman's attitude towards gender-equality did not significantly increase her odds of spending more time fetching water. In other words, whether or not a woman believed that domestic and care work should be distributed equally among men and women, they were just as likely report long water fetching times. A change in attitude is a step in the right direction; however, with regards to gender equality, it is often a timely process to transform those attitudes into practices [34]. Also, initiatives to ensure similar attitude changes among men will be essential in the redistribution of responsibilities within the household [35].

Finally, mothers with no group membership reported more time fetching water. Their lack of free time likely makes it difficult to partake in such activities. This is problematic since group participation provides women with the opportunity to get together in a moment of independence and freedom to think about and discuss the issue as a community [36]. Women's participation with regards to the planning, implementation and maintenance of water and sanitation services is particularly important. In fact, "an evaluation of 122 water projects found that the effectiveness of a project was six to seven times higher where women were involved than where they were not" [23]. Plus, when women have the opportunity to participate in local governments or in positions of leadership more resources tend to be invested in women's issues, including access to safe drinking water and sanitation [37].

Certain limitations may influence interpretation. Firstly, the cross-sectional nature of the study allows for the identification of associations; however, no causal inferences can be made. Additionally, due to its use of a cross-sectional approach, the current study is not able to identify changes over time. Secondly, it is important to bear in mind the possibility of bidirectional relationships between dependent and independent variables. The present research does not allow for the direction of the associations revealed to be established. Additionally, there were no questions about women's physical or mental health.

\section{CONCLUSION}

Water is not a commodity but rather a human right. Access to clean water in or near the home is essential for the well-being of women and their children. When Ethiopian mothers spent 30 minutes or less on water collection, both they and their children had better nutritional outcomes, and they were more likely to engage in positive care practice. The relationship between empowerment indicators and time fetching water were more ambiguous; however, it does seem that when women spend less time fetching water they have greater opportunities for group participation. More initiatives are needed to ensure that all individuals have access to clean, safe water in the future. These programs need not only recognize women's 
participation in accessing water, gender mainstreaming approaches are also required to address power relations and cultural norms in order to effectively implement sustainable water management programs. Taking a gender approach to water management will help ensure that all people, regardless of gender, benefit from, and are empowered by, improved water services.

\section{ACKNOWLEDGEMENT}

This manuscript is based on a project called GROW funded by CARE CANADA in 2016 in Ethiopia. The authors would like to thank their colleagues from CARE CANADA.

\section{REFERENCES}

[1] Pullan, R., Freeman, M., Gething, P. \& Brooker, S., Geographical inequalities in use of improved drinking water supply and sanitation across Sub-Saharan Africa: mapping and spatial analysis of cross-sectional survey data. PLoS Medicine, 11(4), 2014. e1001626.

[2] Stevenson, E., Ambelu, A., Caruso, B., Tesfaye, Y. \& Freeman, M., Community water improvement, household water insecurity, and women's psychological distress: an intervention and control study in Ethiopia. PloS one, 11(4), 2016. e0153432.

[3] Stevenson, E., Greene, L., Maes, K., Ambelu, A., Tesfaye, Y.A. \& Rheingans, R. et al., Water insecurity in 3 dimensions: An anthropological perspective on water and women's psychosocial distress in Ethiopia. Social Science \& Medicine, 75(2), pp. 392400, 2012.

[4] Bratanow, T. \& De Grande, G., Numerical analysis of normal stresses in nonNewtonian boundary layer flow, ENGAN</cja:jid>. Engineering Analysis, 2(1), pp. 20-25, 1985.

[5] Bisung, E. \& Elliott, S., Psychosocial impacts of the lack of access to water and sanitation in low-and middle-income countries: a scoping review. Journal of Water and Health, 15(1), pp. 17-30, 2017.

[6] Golovaty, I., Jones, L., Gelaye, B., Tilahun, M., Belete, H. \& Kumie, A. et al., Access to water source, latrine facilities and other risk factors of active trachoma in Ankober, Ethiopia. PLoS One, 4(8), 2009. e6702.

[7] Mengesha, A., Wubshet, M. \& Gelaw, B., A survey of bacteriological quality of drinking water in North Gondar. The Ethiopian Journal of Health Development (EJHD), 18(2) 2017.

[8] Mohammed, E.K., Major women's right issues in Ethiopia: examining efficiency of the law and its enforcement. International Journal of Human Rights and Constitutional Studies, 5(1), pp. 43-59, 2017.

[9] Sorenson, S., Morssink, C. \& Campos, P., Safe access to safe water in low income countries: water fetching in current times. Social Science \& Medicine, 72(9), pp. 15221526, 2011.

[10] Dickinson, T., Becerra, T. \& Lewis, S., Democracy Works: Joining Theory and Action to Foster Global Change. Boulder, Paradigm: CO, 2015.

[11] Crow, B., Swallow, B. \& Asamba, I., Community organized household water increases not only rural incomes, but also men's work. World Development, 40(3), pp. 528-541, 2012.

[12] Demie, G., Bekele, M. \& Seyoum, B., Water accessibility impact on girl and women's participation in education and other development activities: the case of Wuchale and Jidda Woreda, Ethiopia. Environmental Systems Research, 5(1), p. 11, 2016. 
[13] Pickering, A. \& Davis, J., Freshwater availability and waterfetching distance affect child health in sub-Saharan Africa. Environmental Science \& Technology, 46(4), pp. 23912397, 2012.

[14] Cook, J., Kimuyu, P. \& Whittington, D., The costs of coping with poor water supply in rural Kenya. Water Resources Research, 52(2), pp. 841-859, 2016.

[15] Graham, J., Hirai, M. \& Kim, S-S., An Analysis of water collection labor among women and children in 24 Sub-Saharan African countries. PloS one, 11(6), 2016. $\mathrm{e} 0155981$.

[16] Ververs, M-t, Antierens, A., Sackl, A., Staderini, N. \& Captier, V., Which anthropometric indicators identify a pregnant woman as acutely malnourished and predict adverse birth outcomes in the humanitarian context? PLOS Currents Disasters, 2013.

[17] WHO. WHO Anthro (Version 3.2.2, January 2011) and Macros, Online. Retrieved from: http://www.who.int/childgrowth/software/en/.

[18] Ali, I., Mekete, G. \& Wodajo, N., Intestinal parasitism and related risk factors among students of Asendabo Elementary and Junior Secondary school, South Western Ethiopia. The Ethiopian Journal of Health Development (EJHD), 13(2), pp. 1-7, 2017.

[19] Hutton, G., Haller, L. \& Bartram, J., Global cost-benefit analysis of water supply and sanitation interventions. Journal of Water and Health, 5(4), pp. 481-502, 2007.

[20] Nauges, C. \& Strand, J., Water Hauling and Girls' School Attendance: Some New Evidence from Ghana. Environmental and Resource Economics, 66(1), pp. 65-88, 2017.

[21] Blackden, C.M. \& Wodon, Q., Gender, time use, and poverty in sub-Saharan Africa, World Bank Publications, 2006.

[22] Bryden, M., Situation Report on Region 2 (Afar National Regional State), Emergencies Unit for Ethiopia, 1996, Online. Retrieved from: http://www.africa.upenn.edu/eue_web/AFAR1A.htm.

[23] UNICEF. Gender and water, sanitation and hygiene (WASH), UNICEF, Online. Retrieved from: https://www.unicef.org/esaro/7310_Gender_and_WASH.html.

[24] Tinker, I., The real rural energy crisis: women's time. The Energy Journal, 8, pp. 125146, 1987.

[25] Ruel, M., Harris, J. \& Cunningham, K., Diet quality in developing countries. Diet Quality, Springer, pp. 239-261, 2013.

[26] Arimond, M., Wiesmann, D., Becquey, E., Carriquiry, A., Daniels, M. \& Deitchler, M. et al., Simple food group diversity indicators predict micronutrient adequacy of women's diets in 5 diverse, resource-poor settings. The Journal of Nutrition, 140(11), 2010. 2059S-69S.

[27] Korkalo, L., Erkkola, M., Heinonen, A., Freese, R., Selvester, K. \& Mutanen, M., Associations of dietary diversity scores and micronutrient status in adolescent Mozambican girls. European Journal of Nutrition, pp. 1-11, 2016.

[28] Von Grebmer, K., Saltzman, A., Birol, E., Wiesman, D., Prasai, N. \& Yin, S. et al., 2014 Global Hunger Index: The challenge of hidden hunger, IFPRI books, 2014.

[29] Batliwala, S. \& Dhanraj, D., Gender myths that instrumentalise women:a view from the Indian frontline. Ids Bulletin, 35(4), pp. 11-18, 2004.

[30] Mbwana, H., Kinabo, J., Lambert, C. \& Biesalski, H., Factors influencing stunting among children in rural Tanzania: an agro-climatic zone perspective. Food Security, 9(43), pp. 1-15, 2017.

[31] Ivens, S., Does increased water access empower women? Development, 51(1), pp. 6367, 2008. 
[32] Singh, N., Jacks, G. \& Bhattacharya, P., eds. Women and community water supply programmes: An analysis from a socio-cultural perspective. Natural Resources Forum, Wiley Online Library, 2005.

[33] Sultana, F., Fluid lives: subjectivities, gender and water in rural Bangladesh. Gender, Place and Culture, 16(4), pp. 427-444, 2009.

[34] Rani, M., Bonu, S. \& Diop-Sidibe, N., An empirical investigation of attitudes towards wife-beating among men and women in seven sub-Saharan African countries. African Journal of Reproductive Health, 8(3), pp. 116-136, 2004.

[35] Reij, C. \& Waters-Bayer, A., Farmer innovation in Africa: a source of inspiration for agricultural development, Earthscan Publications: London, Sterling, VA, 2001.

[36] Costa, J., Hailu, D., Silva, E. \& Tsukada, R., The implications of water and electricity supply for the time allocation of women in rural Ghana. Working Paper, International Policy Centre for Inclusive Growth, 2009.

[37] Jalal, I., Women, Water, and Leadership, Online. Retrieved from: https://thinkasia.org/bitstream/handle/11540/2372/women-water-and-leadership.pdf? sequence=1 . 